\title{
Acellular Dermal Matrix and GIngival Connective in the Treatment of Periodontal Recessions - Comparative Clinical Evaluation in Humans
}

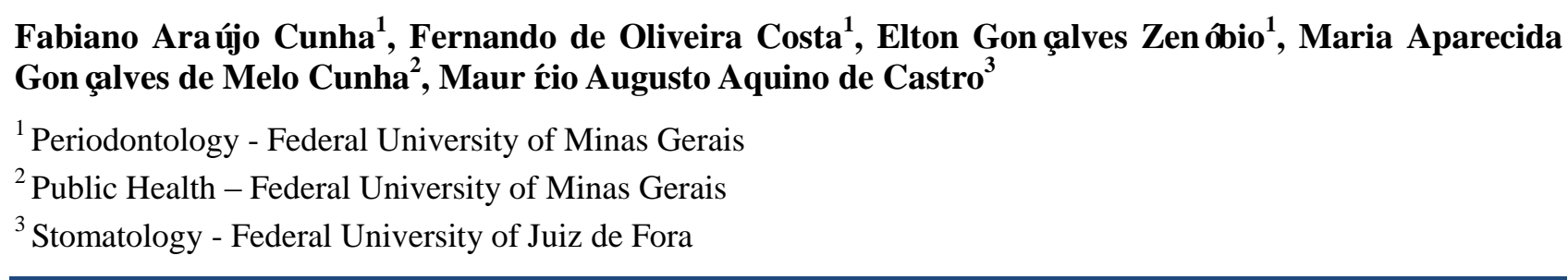

\begin{abstract}
Different periodontal surgical techniques have been proposed for the treatment of periodontal recessions. Among these, the graft of gingival connective tissue stands out for the high predictability of success. This work compared the clinical outcomes of treatment of periodontal recessions, using the gingival connective tissue grafts and acellular dermal matrix. A total of 72 recessions constituted the sample, divided equally into 2 groups. Group 1: treated with acellular dermal matrix graft (MDA) associated with the displaced: Group 2: treated with gingival connective tissue graft, also associated with the flap offset coronally. We evaluated the clinical parameters of probing depth, insert, clinical periodontal recession towards coronal-apical diameter mesio-distal of recessions, keratinized and mucosa thickness flap and influence of grafts in relation to root coverage. The initial measures were compared to those obtained with 45 , 90 and 120 days after surgery. No statistically significant differences were found between the groups in terms of reduction of periodontal recessions, keratinized and mucosa flap thickness and of grafts in relation to root coverage. The Group 2 (CG) showed statistically significant reduction in the depth of drilling and clinical level of insertion, compared to group 1 (MDA). However, these differences were not clinically relevant. It was concluded that both the gingival connective tissue graft as the acellular dermal matrix can be used in the treatment of periodontal recessions, with a high predictability of success.
\end{abstract}

Keywords: Gingival Recession; Connective Tissue Graft; Acellular Dermal Matrix; Periodontal Surgery; Gum Recession; Root Coverage.

\section{Introduction}

Among the mucogingival problems, periodontal recessions stand out with higher prevalence. Are characterized by migration of gingival margin to a position beyond amelocemental junction, resulting in a larger clinic and may also occur to hyperesthesia, greater susceptibility to dentin caries, root greater accumulation of plaque and inflammation ${ }^{[1]}$.

The little ribbon keratinized mucosa height entered the etiology of periodontal recessions. This type of injury can have as etiology traumatogenic occlusion, dental alignment, incorrect brushing, muscle insertions and flanges $[2,3]$

Copyright (C) 2018 Fabiano Araújo Cunha et al.

doi: 10.24294/as.vli2.189

EnPress Publisher LLC.This work is licensed under the Creative Commons Attribution-NonCommercial 4.0 International License (CC BY-NC 4.0). http://creativecommons.org/licenses/ by/4.0
Epidemiological studies have revealed wide variation of 7 to $40 \%$ in the prevalence of periodontal recession, with a tendency to increase with age and greater severity and prevalence in people with good oral hygiene $^{[4,5]}$.

Root coating procedures represent an important aspect in periodontal therapy to periodontal recessions fixes with aesthetic, elimination of root sensitivity and reducing the risk of development of carious lesions on exposed root surfaces ${ }^{[6]}$. 
The search for an effective treatment of periodontal recessions resulted in the emergence of new techniques. In this way, more predictable results as for the root coating could be obtained from the use of techniques such as the gingival connective tissue grafts $^{[7,8]}$, guided tissue regeneration 9-11 and acellular dermal $\operatorname{matrix}^{[12-14]}$.

In an article reviewing the surgical advances in coverage of exposed roots, the authors ${ }^{[15]}$ conclude that the gingival connective tissue graft has great predictability of success in the treatment of periodontal recessions, and that, in most cases, should be the procedure of choice.

The introduction of the technique of gingival connective tissue graft determined more predictability in the treatment of periodontal recessions. The advantage of this procedure is related to the dual blood supply, flap that covers both the graft and the connective tissue that covers the surgical bed, plus a gingival coloration closer to adjacent tissues, eliminating the appearance of "keloid", observed after the placing of a gingival graft of connective more epithelium. However, a surgical procedure is necessary, since this technique uses the Palatine as donor area tissue, increasing the risk of postoperative complications such as pain and rupture of blood vessels palatine ${ }^{[16]}$.

The authors ${ }^{[17,18]}$ investigated the use of acellular dermal matrix as a possible replacement of the palatine connective tissue. This fabric is obtained by means of a strict skin processing of human donors, in which the epidermis and all the cellular elements of the dermal are removed, resulting in a matrix of connective tissue intact and biocompatible ${ }^{[19]}$.

The authors ${ }^{[20-22]}$ investigated the use of allogenic acellular dermal matrix graft as substitute of the Palatine, in the connective tissue covering of root surfaces. That way, you could eliminate the additional surgical procedure of removing the connective tissue palatine and present the advantage of enabling the veneering of multiple recessions, since the acellular dermal matrix is presented in different dimensions, eliminating the difficulty of obtaining a greater area of connective tissue donor.

The use of acellular dermal matrix grafting has been studied for both the root covering how to increase the range of keratinized gingiva around the teeth and implants ${ }^{[23-25]}$.

Some authors ${ }^{[26,27]}$ pointed out how acellular dermal matrix advantage in relation to gingival connective tissue, the ability to perform surgical procedures in multiple sites affected, complicating factor when using the graft gingival connective tissue donor for the limitation and its significant morbidity.

The acellular dermal matrix has been used with success in the medical field, in burn surgery, since 1992, and periodontal surgery since $1994^{[28]}$. However, there are few studies relating the use of dermal matrix in the treatment of periodontal recessions, evaluating clinical parameters such as degree of root coverage, reducing the depth of drilling and keratinized mucosa gain inserted by no means standardized methodolo$\mathrm{gy}^{\text {[29-31] }}$.

Before the exposed in the literature, this work aims to contribute to a greater understanding of the effectiveness of this new graft material in the treatment of periodontal recessions, comparing it with a classic technique of gingival connective tissue graft.

\section{Methodology}

\section{The ethics and research committee}

This work has been prepared in accordance with the standards and guidelines of the resolution 196/96 of the National Health Council, being the work approved by the ethics and Research Committee of the Pontifical Catholic University of Minas Gerais (COEP-OD03 2003).

\section{Sample}

18 patients were selected from the clinic of Periodontics at the dentistry school at PUC-MG, of both sexes, aged from 18 to 50 years old, no smoking, they weren't in orthodontic treatment, Periodontal pockets and that there no submit any systemic involvement which contraindication or alter the periodontal therapy. Were included in the study, patients with periodontal recessions (Figure No. 1) in 13-23, 14-24 and/or 15-25 class I or II of MILLER (Miller, 1985), located in the upper arch contralateral quadrants. The study group totaled 72 bilateral recessions, divided evenly in a group 1 (acellular dermal matrix) and group 2 (gingival connective tissue), at random for the study. 


\section{Assessment periods}

This has a prospective randomized study, in which initial steps were taken, compared to those obtained in subsequent periods the procedure test on 45, 90 and 120 days.

\section{Clinical evaluations}

The clinical parameters recorded in all patients (Group 1 and 2) were the following: index of bleeding on probing (ISS), clinical level insert (NCI), probing depth (PS), periodontal recession towards coronal-apical (RP)-figure $\mathrm{n}^{\mathbf{0}} 2$, diameter mesio-distal periodontal recession (RPMD) - figure $n^{\circ} 3$, periodontal recession in the coronal-apical direction, after the offset of the flap (RPA)-figure $n^{\circ} 4$, diameter mesio-distal periodontal recession after the offset of the flap (RRL) - figure $\mathrm{n}^{\circ} 5$, amount of keratinized mucosa inserted (MCI), evidenced through the solution of Schiller, thickness of the initial retail (related to root coverage) and thickness of the graft (related to root coverage).

\section{Surgical procedure}

The surgical procedure used was the same for both groups, based on Harris (1992), and the corresponding Group 1 dealt with recessions through the acellular dermal matrix graft (Alloderm, LifeCell Corporation, USA), while in Group 2 used the gingival connective tissue graft.

The surgical technique chosen was the proposal by Harris (1992), which consists in carrying out horizontal incisions, with blade number $15 \mathrm{c}$ (Prudent), at the time of the cement-enamel junction, joined later by a intra-sulcular incision. For greater mobility of the flap, relaxing incisions were created for mesial and distal. The incision was performed so bevel, providing a partial thickness flap. All papillary epithelium was removed, aiming at that location, the adaptation and flap healing repositioned coronally. After partial thickness flap, the root surface was instrumented by means of curettes type Gracey 5-6 and 7-8 (Prudent) and planed with multilaminate, with the goal of decreasing the convexity of the root, under abundant irrigation with saline. This procedure is very important because it decreases the size of the recession in the horizontal direction and, consequently, the area to be covered, by reducing the perimeter of the exposed portion of the root at this time, the chemical treatment of the root through the application of an EDTA gel to $24 \%$ for two minutes, and then removing the excess gel with sterile gauze followed by abundant root surface irrigation with saline (32). After removal of the gingival connective tissue (Group 1), this was adapted on the previously exposed root surface and positioned on the cement-enamel junction, through a suture stoves. The flap was moved and sutured coronally, in order to cover all the connective tissue. In cases where the acellular dermal matrix was used, there was the need for hydration the same in saline solution, followed by the guidelines of the manufacturer. After the identification of the side of the acellular dermal matrix corresponding to the basal membrane, this was cut according to the dimensions of the surgical bed and adapted on the root surface with the side corresponding to the basal membrane facing the flap. At that moment, we perform a slight compression with sterile gauze for 3 to 5 minutes. The graft remained in position by means of an attached string suture accomplished with Vicryl absorbable thread 5.0 (Ethicon). Subsequently, the flap was positioned and sutured coronally, in order to cover all the graft of acellular dermal matrix.

After surgical procedures, patients received postoperative care instructions to prevent irritation of the surgical area through Atraumatic brushing, prescribing-if food intake light and Pasty, as well as the use of amoxicillin $500 \mathrm{mg} 3$ times a day for 1 week, and chlorhexidine digluconate gel to $0.12 \%$ during 15 days (figures no. 6 to 15 ).

\section{Revaluations}

Patients were reassessed to 45, 60, 90 and 120 days after surgical procedures and new clinical data (ISS, PS, NCI, RP, RPMD, RPA, RRL and MCI) recorded in his own record.

\section{Statistical analysis}

Comparisons between the two treatment groups (gingival connective and acellular dermal matrix) as to the depth of probing, periodontal recession towards coronal-apical and mesiodistal, periodontal recession towards coronal-apical and mesiodistal after opening of the flap distal, clinical level and amount of keratinized mucosa inserted were performed using the Mann-Whitney test. It should be noted that this comparison was performed considering each of the evalua- 
tions. It was performed an evaluation of the evolution of the measures of interest: probing depth, periodontal recession towards coronal-apical and mesiodistal, periodontal recession towards coronal-apical and mesiodistal after opening, flap distal clinical and amount of keratinized mucosa inserted. This analysis was performed using Friedman's test. Using the Pearson correlation coefficient ( $r$ ) with the objective of assessing the relationship between periodontal recession towards coronal-apical and mesio-distal, and the thickness of the flap and the graft.

All results were considered significant to a probability less than $5 \%$ significance $(\mathrm{p}<0.05)$. And so, at least $95 \%$ confidence in the conclusions drawn.

\section{Results/Discussion}

\section{In relation to the experimental design}

In relation to the experimental design, it is essential to separate the non-controlled studies, represented by clinical case reports, comparative controlled studies.

Some authors ${ }^{[12,13,17,19,21,25]}$ evaluated the degree of root coating, using the technique of gingival connective tissue graft in samples ranged from 12 to 245 recessions. These studies, clinical case reports, did not follow a scientific methodology that standardization would allow the comparison of clinical data obtained before and after surgical procedures.

There are few studies that provide all the measurements and parameters required to evaluate critically the ability and the predictability of root coverage, the ability to improve the clinical attachment level and the variation in the amount of keratinized mucosa inserted [7,9].

Some authors ${ }^{[3,4,5,9,10]}$ conducted comparative studies between different surgical techniques in the treatment of periodontal recessions. These studies evaluated the clinical parameters in a period of 6 months $^{[4]}$ to 60 months $^{[10]}$.

Similarly, many are jobs that assessed clinical parameters, after surgeries of acellular dermal matrix grafting in patients with periodontal recessions, however, in isolated clinical cases and comparative not.

\section{Probing depth}

In both groups was observed a significant reduction of the probing depth considering the initial assessment in relation to the other. The group treated with gingival connective tissue graft presented average depth of $1.0 \mathrm{~mm}$, polling $0.6 \mathrm{~mm}, 0.6 \mathrm{~mm}$ and $0.5 \mathrm{~mm}$ respectively at the initial exam, to 45, 90 and 120 days. The group treated with acellular dermal matrix graft presented average depth of $1.0 \mathrm{~mm}$ probe, $0.9 \mathrm{~mm}, 0.8$ $\mathrm{mm}$ and $0.8 \mathrm{~mm}$ respectively at the initial exam, to 45 , 90 and 120 days.

Comparison between the groups, it was verified that the group treated with gingival connective tissue graft, presented lowest depth of probing to 90 and 120 days. This difference was shown to be statistically significant (tables I and II).

It should be noted that in the group treated with acellular dermal matrix grafting, from 45 days after surgery until the end of the experiment (120 days), there was a tendency to stabilization of results of probing depth.

These results are similar to the work of ${ }^{[7]}$, in which the authors found reduced probing depth index in 2 groups of recessions treated with acellular dermal matrix grafting and gingival connective, after 3 and 6 months. The authors found a highest average probing depth at the end of the study, in the group that received the graft of acellular dermal matrix, but without statistical significance.

These results can be evaluated in tables I and II.

\begin{tabular}{|l|c|c|c|c|c|c|c|}
\hline & & \multicolumn{5}{|c|}{ Descriptive measures } \\
\hline Time & Group & Minimum & Maximum & Median & Average & d.p. & P \\
& & & & & & & \\
\hline \multirow{3}{*}{$T_{0}$} & $C G$ & 0.5 & 2.0 & 1.0 & 1.0 & 0.4 & 0.9580 \\
& & & & & & & \\
\cline { 2 - 8 } & $M D A$ & 0.5 & 1.5 & 1.0 & 1.0 & 0.3 & CG = MDA \\
\hline
\end{tabular}




\begin{tabular}{|c|c|c|c|c|c|c|c|}
\hline \multirow[b]{2}{*}{$T_{45}$} & $C G$ & 0.0 & 1.0 & 0.8 & 0.6 & 0.4 & 0.0964 \\
\hline & $M D A$ & 0.5 & 1.0 & 1.0 & 0.9 & 0.2 & CG = MDA \\
\hline \multirow{2}{*}{$T_{90}$} & $C G$ & 0.0 & 1.0 & 0.5 & 0.6 & 0.4 & 0.0369 \\
\hline & $M D A$ & 0.5 & 1.0 & 1.0 & 0.8 & 0.2 & $\mathrm{MDA}>\mathrm{CG}$ \\
\hline \multirow{2}{*}{$T_{120}$} & $C G$ & 0.0 & 1.0 & 0.5 & 0.5 & 0.4 & 0.0347 \\
\hline & $M D A$ & 0.5 & 1.0 & 1.0 & 0.8 & 0.3 & MDA > CG \\
\hline & & & & & & & \\
\hline
\end{tabular}

Table 1. Descriptive and comparative measures of probing depth (PS), by time in $\mathrm{mm}$

\begin{tabular}{|c|c|c|c|c|c|c|c|}
\hline & & & & Descrip & measures & & \\
\hline Group & Time & Minimum & Maximum & Median & Average & d.p. & $\mathbf{p}$ \\
\hline \multirow{5}{*}{ CG } & $T_{0}$ & 0.5 & 2.0 & 1.0 & 1.0 & 0.4 & 0.000 \\
\hline & $T_{45}$ & 0.0 & 1.0 & 0.8 & 0.6 & 0.4 & \\
\hline & $T_{90}$ & 0.0 & 1.0 & 0.5 & 0.6 & 0.4 & \\
\hline & $T_{120}$ & 0.0 & 1.0 & 0.5 & 0.5 & 0.4 & \\
\hline & & \multicolumn{6}{|c|}{$T_{0}>T_{45}, T_{90}, T_{120} / T_{45}>T_{120}$} \\
\hline \multirow{5}{*}{ MDA } & $T_{0}$ & 0.5 & 1.5 & 1.0 & 1.0 & 0.3 & 0.008 \\
\hline & $T_{45}$ & 0.5 & 1.0 & 1.0 & 0.9 & 0.2 & \\
\hline & $T_{90}$ & 0.5 & 1.0 & 1.0 & 0.8 & 0.2 & \\
\hline & $T_{120}$ & 0.5 & 1.0 & 1.0 & 0.8 & 0.3 & \\
\hline & & \multicolumn{6}{|c|}{$T_{0}>T_{45}=T_{90}=T_{120}$} \\
\hline
\end{tabular}

Table 2. Descriptive and comparative measures of probing depth (PS) group in mm 
Periodontal recession in the coronal-apical direction

We're not observed significant differences between the two studies groups for periodontal recession in the coronal-apical sense at all reviews performed. For the evolution throughout the study showed a continuous decrease with each new survey.

As for root coverage was seen in the group that received gingival connective, $83 \%$ average coverage and, in the group that received acellular dermal matrix, an average of $71.9 \%$ coverage. It should be noted that these data are for the groups evaluated in isolation, not with percentage comparisons.

The Group 1 (acellular dermal matrix) showed an average of periodontal recession towards coronal-apical $2.9 \mathrm{~mm}$ at initial examination; $1.0 \mathrm{~mm}$ to 45 days; $0.8 \mathrm{~mm}$ to $0.6 \mathrm{~mm}$ to 90 days and 120 days of evaluation.

The Group 2 (gingival connective) showed an average of periodontal recession towards coronal-apical $3.4 \mathrm{~mm}$ at initial examination; $0.7 \mathrm{~mm}$ to 45 days; 0.7 $\mathrm{mm}$ to $0.6 \mathrm{~mm}$ to 90 days and 120 days of evaluation.

The studies of ${ }^{[23,24,25,27]}$ evaluated the degree of root coating on teeth with periodontal recessions, submitted to the technique of acellular dermal matrix grafting. The average root coverage ranged from $96 \%{ }^{[23,24]}$ to $100 \%{ }^{[25,27]}$.

The author ${ }^{[13]}$ assessed the degree of root covering achieved in 2 distinct groups of treatment. The Group1 received treatment with gingival connective tissue graft and the Group 2 was treated with acellular dermal matrix grafting. The sample totaled 107 recessions. The Group submitted to the graft procedure gingival connective tissue showed an average root coverage of $96.2 \%$, while the group who received the graft of acellular dermal matrix has reached a average of $95.8 \%$, being this difference statistically nonsignificant. The same way ${ }^{[18]}$ compared gingival connective and matrix grafts acellular dermal in 30 recessions divided evenly into 2 groups. The evaluations were performed at 3 and 6 months postoperatively. The average covering degree with the root acellular dermal matrix was $66.5 \%$, while the group who received the graft of gingival connective tissue of $64.9 \%$, and this difference not significant. In this study, statistical analysis of the results of periodontal recessions (related to the degree of root coating), demonstrated a reduction of periodontal recessions in both groups, with statistical significance. This reduction was shown with each new solid evaluation (45.90 and 120 days). However, comparisons between the groups were not observed reduction of the height and width of the periodontal recessions that were statistically significant. These results are similar to those of study ${ }^{[31]}$, which found no significant differences in relation to the root coverage between 2 groups of recessions treated with acellular dermal matrix grafts and gingival connective, after 3 months of evaluation. This similarity of results demonstrates that both procedures can be clinically effective.

\section{Mesiodistal diameter of periodontal recessions}

In the initial assessment, differences were observed between the two groups as the diameter of the periodontal recessions: the group that received the graft of gingival connective tissue showed superior results (average of $3.4 \mathrm{~mm}$ ) compared to the group that received the graft of acellular dermal matrix (average of $2.7 \mathrm{~mm})$.

Similarly to the periodontal recession, there was a continuous reduction of the mesiodistal diameter of the periodontal recessions. The Group 1 (acellular dermal matrix) showed an average towards the mesio-distal periodontal recessions of $2.7 \mathrm{~mm}$ at initial examination; $0.9 \mathrm{~mm}$ to 45,90 and 120 days.

The Group 2 (gingival connective) showed an average towards the mesio-distal periodontal recessions of $3.4 \mathrm{~mm}$ at initial examination; $0.5 \mathrm{~mm}$ to 45,90 and 120 days.

It should be noted that whereas the initial assessment in relation to the end, there was no difference in reducing the diameter of the mesio-distal periodontal recessions between gingival connective groups and acellular dermal matrix.

Periodontal recession towards coronal-apical after opening of the flap and mesiodistal diameter of the distal periodontal recessions after opening of the flap

The two study groups, evaluated in isolation, presented a significant increase of periodontal recessions 
both in the coronal-apical direction as towards mesio-distal, compared between the initial exam and immediately after the opening of the flap.

In the group that received the graft of gingival connective tissue, it was verified that the periodontal recessions (coronal-apical direction), when the opening of the flap, showed an average of $77.8 \%$ increase compared to the initial exam. In relation to the diameter of the mesio-distal periodontal recessions, this same group presented an increase of $97.2 \%$ compared to the initial exam.

In the group that received the graft of acellular dermal matrix, it was verified that the periodontal recessions (coronal-apical direction), when the opening of the flap, showed an average of $62 \%$ increase in relation to the initial exam. In relation to the diameter of the mesio-distal periodontal recessions, this same group presented an increase of $89.5 \%$ compared to the initial exam.
In Group 1 (acellular dermal matrix), recessions in the coronal-apical direction periodontal showed an average of $2.9 \mathrm{~mm}$ in the initial examination, and 5.5 $\mathrm{mm}$ after opening of the flap. In relation to the diameter of the mesio-distal periodontal recessions, this average ranged from $2.7 \mathrm{~mm}$ (initial exam), to $5.0 \mathrm{~mm}$ (after opening of the flap).

In Group 2 (gingival connective), recessions in the coronal-apical direction periodontal showed an average of $3.4 \mathrm{~mm}$ at the initial exam and $5.9 \mathrm{~mm}$ after opening of the flap. In relation to the diameter of the mesio-distal periodontal recessions, this average ranged from $3.4 \mathrm{~mm}$ (initial exam), to $5.2 \mathrm{~mm}$ (after opening of the flap).

The measures of periodontal recessions in the coronal-apical direction and mesio-distal after the opening of the flap, scraping, smoothing and root planing were similar compared between the two groups of interest (tables III and IV).

\begin{tabular}{|c|c|c|c|c|c|c|c|}
\hline \multirow[b]{2}{*}{ Time } & \multirow[b]{2}{*}{ Group } & \multicolumn{6}{|c|}{ Descriptive measures } \\
\hline & & Minimum & Maximum & Median & Average & d.p. & $\mathbf{p}$ \\
\hline \multirow{2}{*}{$T_{0}$} & $C G$ & 1.1 & 5.0 & 3.3 & 3.4 & 1.0 & 0.0846 \\
\hline & $M D A$ & 1.5 & 4.6 & 2.9 & 2.9 & 0.8 & CG $=$ MDA \\
\hline \multirow{2}{*}{$T_{45}$} & $C G$ & 0.0 & 1.5 & 0.9 & 0.7 & 0.5 & 0.1490 \\
\hline & $M D A$ & 0.0 & 2.1 & 1.0 & 1.0 & 0.7 & CG $=$ MDA \\
\hline \multirow{2}{*}{$T_{90}$} & $C G$ & 0.0 & 1.5 & 0.8 & 0.7 & 0.4 & 0.3494 \\
\hline & $M D A$ & 0.0 & 2.0 & 0.8 & 0.8 & 0.6 & CG $=$ MDA \\
\hline \multirow{2}{*}{$T_{120}$} & $C G$ & 0.0 & 1.5 & 0.8 & 0.6 & 0.4 & 0.3254 \\
\hline & $M D A$ & 0.0 & 1.9 & 0.8 & 0.8 & 0.6 & CG $=$ MDA \\
\hline
\end{tabular}

Note : The value of $p$ refers to the Mann-Whitney test

Table 3. Descriptive and comparative measures of periodontal recessions in the coronal-apical direction, by time in $\mathrm{mm}$

\begin{tabular}{|l|l|l|l|l|l|l|}
\hline \multicolumn{7}{|l|}{} \\
\hline Descriptive measures \\
\hline Group & Minimum & Maximum & Median & Average & d.p. & \\
\hline MG & 67.8 & 100.0 & 79.3 & 83.0 & 11.0 & \\
\hline
\end{tabular}

Notes: 1. p value refers to the Mann Whitney test. 2. Were observed 12 teeth with periodontal recession full (100\%).

Table 4. Descriptive measures in percentage of periodontal recessions concerning the degree of root, covering the period from the initial exam and 120 days post-op

\section{Clinical level of insertion}

In both groups, was observed a significant reduction of the level of insertion of each new assessment.
The clinical level of insertion was significantly different between the groups of interest, with best results in cases where it was used the acellular dermal 
matrix grafting. It should be noted that these results were verified in the evaluations carried out with 45,90 and 120 days after the surgical procedure. In the initial assessment, there was no significant difference.

The Group 1 (acellular dermal matrix) presented the clinical level average of $3.9 \mathrm{~mm}$ insertion in the initial examination; $1.9 \mathrm{~mm}$ to 45 days; $1.7 \mathrm{~mm}$ to 1.6 $\mathrm{mm}$ to 90 days and 120 days of evaluation.

The Group 2 (gingival connective) presented the clinical level average of $4.4 \mathrm{~mm}$ insertion in the initial examination; $1.3 \mathrm{~mm}$ to 45 days; $1.1 \mathrm{~mm}$ to 90 days and $1.1 \mathrm{~mm}$ to 120 days (table $\mathrm{V}$ ).

\begin{tabular}{|c|c|c|c|c|c|c|c|}
\hline \multirow[b]{2}{*}{ Group } & \multirow[b]{2}{*}{ Time } & \multicolumn{6}{|c|}{ Descriptive measures } \\
\hline & & Minimum & Maximum & Median & Average & d.p. & $\mathbf{p}$ \\
\hline \multirow{5}{*}{ CG } & $\mathrm{T}_{0}$ & 2.1 & 6.0 & 4.4 & 4.4 & 1.0 & 0.000 \\
\hline & $\mathrm{T}_{45}$ & 0.1 & 2.1 & 1.2 & 1.3 & 0.6 & \\
\hline & $\mathrm{T}_{90}$ & 0.1 & 2.0 & 1.1 & 1.1 & 0.6 & \\
\hline & $\mathrm{T}_{120}$ & 0.1 & 1.9 & 1.1 & 1.1 & 0.6 & \\
\hline & & \multicolumn{6}{|c|}{$T_{0}>T_{45}>T_{90}>T_{120}$} \\
\hline \multirow{5}{*}{ MDA } & $\mathrm{T}_{0}$ & 2.5 & 5.6 & 3.5 & 3.9 & 0.9 & 0.000 \\
\hline & $\mathrm{T}_{45}$ & 0.5 & 3.1 & 2.0 & 1.9 & 0.8 & \\
\hline & $\mathrm{T}_{90}$ & 0.5 & 3.0 & 1.6 & 1.7 & 0.6 & \\
\hline & $\mathrm{T}_{120}$ & 0.5 & 2.9 & 1.4 & 1.6 & 0.7 & \\
\hline & & \multicolumn{6}{|c|}{$T_{0}>T_{45}>T_{90}>T_{120}$} \\
\hline
\end{tabular}

\section{Note: $p$ value refers to the Friedman test}

Table 5. Descriptive and comparative measures of clinical level insert (NCI), per group in mm

These results are similar to studies of $(15,18)$, they found significant differences between teeth with periodontal recession treated with acellular dermal matrix grafts and gingival connective, after 3 months of evaluation, but no significant clinical value.

\section{Amount of keratinized mucosa inserted}

In relation to the amount of keratinized mucosa entered does not have been noted significant differences between the two groups of interest, in all the evaluations carried out. However, it was observed a progressive increase over the course of the study, having significant differences between each new evalua- tion in the group that received the graft of gingival connective tissue. In the group that received the graft of acellular dermal matrix showed stability in the last two evaluations (90 and 120 days).

The Group 1 (acellular dermal matrix) presented the keratinized mucosa range entered (height), $2.7 \mathrm{~mm}$ at initial examination; $2.8 \mathrm{~mm}$ to 45,90 and 120 days.

The Group 2 (gingival connective) presented the keratinized mucosa range entered (height), $2.2 \mathrm{~mm}$ in the initial examination; $2.6 \mathrm{~mm}$ to 45 days; $2.7 \mathrm{~mm}$ to $2.8 \mathrm{~mm}$ to 90 days and 120 days (table VI).

\begin{tabular}{|l|l|l|l|l|l|l|l|}
\hline \multicolumn{7}{|c|}{ Descriptive measures } \\
\hline \multirow{3}{*}{$\mathrm{T}_{0}$} & Material & Minimum & Maximum & Median & Average & d.p. & P \\
\hline \multirow{3}{*}{} & CG & 1.1 & 3.1 & 2.4 & 2.2 & 0.7 & 0.0738 \\
\cline { 2 - 9 } & MDA & 1.2 & 4.0 & 2.8 & 2.7 & 0.8 & CG $=$ MDA \\
\hline \multirow{3}{*}{$\mathrm{T}_{45}$} & & & & & & & \\
\hline \multirow{3}{*}{$\mathrm{T}_{90}$} & CG & 1.4 & 3.7 & 2.6 & 2.6 & 0.6 & 0.6350 \\
\cline { 2 - 9 } & MDA & 1.2 & 4.1 & 2.9 & 2.8 & 0.8 & CG $=$ MDA \\
\hline & & & & & & & \\
\cline { 2 - 9 } & MDA & 1.5 & 3.7 & 2.9 & 2.7 & 0.6 & 0.8868 \\
\hline
\end{tabular}




\begin{tabular}{|l|l|l|l|l|l|l|l|}
\hline \multirow{3}{*}{$\mathrm{T}_{120}$} & $\mathrm{CG}$ & 1.6 & 3.7 & 2.9 & 2.8 & 0.6 & 0.9244 \\
\cline { 2 - 9 } & MDA & 1.3 & 4.1 & 2.9 & 2.8 & 0.8 & $\mathrm{CG}=\mathrm{MDA}$ \\
\hline
\end{tabular}

Note: $p$ value refers to the Mann-Whitney test

Table 6. Descriptive and comparative measures of the amount of keratinized mucosa inserted (MCI), in mm

In the present study, both groups showed an increase in the range of keratinized mucosa, after 3 months of evaluation, of $0.1 \mathrm{~mm}$ for the Group 1 (acellular dermal matrix) and $0.6 \mathrm{~mm}$ for the Group 2 (gingival connective). The work of (2) and (11) state that the time required for a further gain in the range of keratinized mucosa, in recessions the acellular dermal matrix treated, would be greater than those treated with the graft of gingival connective. Possibly, you would need a longer time of evaluation the increase in the range of keratinized mucosa, when they used the acellular dermal grafts.

Several studies have shown that the discussion connective tissue graft contributes to epithelial keratinization of the overlying mucosa flap, with evidence of increase in the amount of keratinized tissue $(26,27,28,30,31)$. However, the mechanism of keratinization of treated areas with acellular dermal matrix graft is still unknown $(4,10)$.

\section{Bleeding on probing index}

Initially, observed, in both groups, 3 cases with bleeding and, after the graft, in all cases, bleeding was not observed.

Correlation between periodontal recession (senses coronal-apical and mesiodistal) and thickness of graft and flap.

No significant relationships were observed between the periodontal recession (senses coronal-apical and mesiodistal) and the thickness of the graft and flap. Changes in measurements of the recessions suffered influence of thickness of the flap and the graft.

It should be noted that this result was checked both at the gingival connective group and the group that received acellular dermal matrix.

\section{Conclusions}

In accordance with the methodology applied and the trial period, it might be concluded that:

-There were no differences between the study groups, the reductions in periodontal recessions coronal-apical and mesiodistal.
-There were no differences between the study groups in relation to the final amount of keratinized mucosa formed.

-The thickness of the flap and of grafts did not influence the root coverage.

-Both the gingival connective tissue graft as the acellular dermal matrix grafting feature high predictability of success in the treatment of periodontal recessions.

\section{References}

1. Bouchard P. Subepithelial connective tissue grafts in the treatment of gingival recessions. A comparative of 2 procedures. Journal of Periodontology. 1994; 65: 929-36.

2. Blomlof J. Effect of different concentrations of EDTA on smear removal and collagen exposure in periodontitis affected root surfaces. Journal of Clinical Periodontology. 1997; 24: 534-37.

3. Callan DP. Use of acellular dermal matrix allograft material in dental implant treatment. Dental Surgery Products. 1996; 10:14-7.

4. Carranza Jr., FA. \&amp; Newman MG. Periodontia Clínica. 1997; 5: 350-83.

5. Dodge JR. Root coverage without a palatal donor site, using an acellular dermal graft. Periodontal Insights. 1998: 5-9.

6. Grisi DC. Enxertos conjuntivo subepitelial e de matriz dérmica acelular no tratamento de recessões gengivais. Revista da Associação Paulista de Cirurgiões Dentistas, 2001; 55:4-9.

7. Harris RJ. The connective tissue and partial thickness double pedicle graft: a predictable method of obtaining root coverage. Journal of Periodontology. 1992; 63:477-86.

8. Harris RJ. The connective tissue with partial thickness double pedicle graft: the results of 100 consecutively treated defects. Journal of Periodontology. 1994; 65: 448-61.

9. Harris RJ. Root coverage with a connective tissue with partial thickness double pedicle graft and an acellular dermal matrix graft: a clinical and histological evaluation of a case report. Journal of Periodontology. 1998; 69: 1305-11.

10. Harris RJ. A comparative study of root coverage obtained with an acellular dermal matrix versus a connective tissue graft: results of 107 recession defects in 50 consecutively treated patients. In- 
ternational Journal of Periodontics and Restaurative Dentistry. 2000; 20: 51-9.

11. Harris RJ. Acellular dermal matrix used for root coverage: 18-month folow-up observation. International Journal of Periodontics Restaurative Dentistry. 2002; 22: 156-63.

12. Henderson RD. Predictable multiple site root coverage using dermal matrix allograft. Journal of Periodontology. 2001; 72: 571-82.

13. Jahnke PV. Thick free gingival and connective tissue autografts for root coverage. Journal of Periodontology. 1993; 64: 315-22.

14. Jepsen KH. Treatment of gingival recession with titanium reinforced barrier membranes versus connective tissue grafts. Journal of Periodontology. 1998; 69: 383-91.

15. Joshipura KJ. Gingival recession: Intra oral distribution and associated factors. Journal of Periodontology. 1994; 65: 864-71.

16. Langer B \&amp; Langer L. Subepithelial connective tissue graft technique for root coverage. Journal of Periodontology. 1985; 56: 715-20.

17. Liversey S. An acellular dermal transplant process from human allograft skin retains normal extracelular matrix components and ultrastructural characteristics. American Association of Tissue Banks Conference. 1994.

18. Miller PD \&amp; Craddock RD. Surgical advances in the coverage of exposed roots. Journal of Periodontology. 1996; 3: 103-8.

19. Nelson, SW. The subpedicle connective tissue graft. A bilaminar reconstructive procedure for the coverage of desnuded root surfaces. Journal of Periodontology. 1987; 58: 95-102.

20. Novaes Jr. Comparative 6-Month Clinical Study of a Subepithelial Connective tissue Graft and Acellular Dermal Matrix Graft for the Treatment of Gingival Recession. Journal of Periodontology. 2001; 72: 1477-84.

21. Oliver MJ. Multiple denuded root surfaces. Complete coverage with a one-stage subepithelial connective tissue graft. Oral Health. 1987; 77: 51-8.

22. Paolantônio M. Subpedicle connective tissue graft versus free gingival graft in the coverage of exposed root surfaces: a 5- year clinical study. Journal of Clinical Periodontology. 1997; 24: 51-6.

23. Paolantônio M. Subpedicle acelular dermal matrix graft in the treatment of gingival recessions: A comparative 1-year clinical study. Journal of Periodontology. 2002; 1299-1307.

24. Pini Prato G. Guided tissue regeneration versus mucogingival surgery in the treatment of human buccal gingival recession. A 4-year folow-up study. Journal of Periodontology. 1996; 67:1216-23.
25. Raetzke PB. Covering localized areas of root exposure employing the envelope technique. Journal of Periodontology. 1985; 56: 897.

26. Rosetti EP. Treatment of gingival recession: comparative study between subepithelial connective tissue graft and guided tissue regeneration. Journal of Periodontology. 2000; 71: 1441-47.

27. Serino G. The prevalence and distribution of gingival recession in subjects with a hight standard of oral hygiene. Journal of Clinical Periodontology. 1994; 21: 57-63.

28. Silvertein LH \&amp; Callan DP. An acellular dermal matrix allograft substitute for palatal donor tissue. Postgrad Dentistry. 1996; 3: 14-21.

29. Silverstein LH. Fundamentally changing soft tissue grafting. In: Dentistry Today. 1997; 16: 3.

30. Stoner J \&amp; Mazdasna S. Gingival recession in lower incisor region of 15- year old subjects. Journal of Periodontology. 1980; 51: 74-6.

31. Tal H. Subgingival acellular dermal matrix allograft for the treatment of gingival recession. Journal of Periodontology. 1999; 70: 1118-24.

32. Wennstrom JL \&amp; Zucchelli G. Increased gingival dimensions, A significant factor for successful outcome of root coverage procedures? A two year prospective clinical study. Journal of Clinical Periodontology. 1996; 23: 770- 7. 